\title{
Are $\mathrm{H}_{2} \mathrm{~S}$-trapping compounds pertinent to the treatment of sulfide poisoning?
}

\author{
Philippe Haouzi ${ }^{1}{ }^{,}$, Candice M. Klingerman ${ }^{2}$, Bruno Chenuel ${ }^{1}$, and Takashi Sonobe ${ }^{1}$ \\ ${ }^{1}$ Department of Medicine, Division of Pulmonary and Critical Care Medicine, Penn State \\ University College of Medicine, Hershey, PA USA \\ ${ }^{2}$ Department of Biological and Allied Health Sciences, Bloomsburg University, Bloomsburg, PA
}

\section{Dear Sir}

We have read with interest the study of Brenner et al. (1) on the effects of the Vitamin B12 analog cobinamide on $\mathrm{H}_{2} \mathrm{~S}$ toxicity. In this study, the effects of various vitamin $\mathrm{B} 12$ analogs were compared using, as the main outcome, the duration of NaHS infusion that can be maintained after administering the antidote until death occurred - or up to a maximum of $270 \mathrm{mg}$.

Although Cobalt compounds belong to a category of antidotes, such as methemoglobin, which do complex $\mathrm{H}_{2} \mathrm{~S}(2,3)$, it is essential to consider their potential clinical benefit in the light of the kinetics and fate of the various pools of sulfides during and following $\mathrm{H}_{2} \mathrm{~S}$ exposure (4). During an infusion of NaHS, a large part of hydrogen sulfide is immediately oxidized in the blood or eliminated by the lungs. What is left equilibrates into 2 main pools: 1- a small "compartment" of free/soluble or exchangeable sulfides, i.e. gaseous $\mathrm{H}_{2} \mathrm{~S}$ and its sulfhydryl anion $\mathrm{HS}^{-}$(4), 2- a large and complex pool of sulfides, which is combined with the cysteine residues of many proteins or with metallo-proteins. Only the free/soluble $\mathrm{H}_{2} \mathrm{~S}$ can be trapped by cobalt compounds. This is why during a continuous infusion of NaHS, any vitamin B12 analog already present in the blood will combine free sulfide as it enters the blood stream. This will reduce the amount of free $\mathrm{H}_{2} \mathrm{~S}$ and the rate at which it would have otherwise diffused into the cells and eventually combined with the cytochrome $\mathrm{c}$ oxidase (akin to the interaction between ferric compounds and soluble sulfide).

However, the pool of free/exchangeable sulfides remains present in the blood only if $\mathrm{H}_{2} \mathrm{~S}$ infusion is maintained (4). As soon as $\mathrm{H}_{2} \mathrm{~S}$ exposure ceases, when for instance a victim is withdrawn from a source of intoxication to be treated by first responders, free $\mathrm{H}_{2} \mathrm{~S}$ drops to undetectable levels within less than a minute (4). This exceptionally rapid disappearance of $\mathrm{H}_{2} \mathrm{~S}$ can be accounted for by the ability of mitochondria to oxidize large amounts of sulfide at a very high rate $(4,5)$. Little benefit is thus to be expected from compounds interacting with the pool of exchangeable sulfide, since all free $\mathrm{H}_{2} \mathrm{~S}$ would have vanished well before any antidote can be administered. Incidentally, the large pool of combined $\mathrm{H}_{2} \mathrm{~S}$, which is not "accessible" to trapping, also decreases rapidly (4).

*Correspondence: Pennsylvania State University College, Dept. of Medicine, Division of Pulmonary and Critical Care Medicine, 500 University Drive, H041, Hershey, PA 17033.717-531-0003 x287593, phaouzi@ hmc.psu.edu. 
Due to the unique behavior of $\mathrm{H}_{2} \mathrm{~S}$ (4), the challenge for treating $\mathrm{H}_{2} \mathrm{~S}$ poisoning is to find an antidote capable of diffusing very rapidly into cells, restoring ATP production, and counteracting or preventing the toxic and post toxic/anoxic injuries to the brain, the heart and the lungs, even in the absence of free sulfide.

\section{Acknowledgments}

This work was supported by the CounterACT Program, National Institutes of Health Office of the Director (NIH OD), and the National Institute of Neurological Disorders and Stroke (NINDS), Grant Number 1R21NS080788-01.

\section{References}

1. Brenner M, Benavides S, Mahon SB, Lee J, Yoon D, Mukai D, Viseroi M, Chan A, Jiang J, Narula $\mathrm{N}$, Azer SM, Alexander C, Boss GR. The vitamin b12 analog cobinamide is an effective hydrogen sulfide antidote in a lethal rabbit model. Clinical toxicology. 2014

2. Truong DH, Mihajlovic A, Gunness P, Hindmarsh W, O'Brien PJ. Prevention of hydrogen sulfide (h2s)-induced mouse lethality and cytotoxicity by hydroxocobalamin (vitamin b(12a)). Toxicology. 2007; 242:16-22. [PubMed: 17976885]

3. Van de Louw A, Haouzi P. Ferric iron and cobalt (iii) compounds to safely decrease hydrogen sulfide in the body? Antioxidants \& redox signaling. 2013; 19:510-516. [PubMed: 22233239]

4. Klingerman CM, Trushin N, Prokopczyk B, Haouzi P. H2s concentrations in the arterial blood during h2s administration in relation to its toxicity and effects on breathing. American journal of physiology Regulatory, integrative and comparative physiology. 2013; 305:R630-638.

5. Bouillaud F, Blachier F. Mitochondria and sulfide: A very old story of poisoning, feeding, and signaling? Antioxidants \& redox signaling. 2011; 15:379-391. [PubMed: 21028947] 